\title{
Social and Psychological Effect of Poverty on Children in Georgia
}

\author{
Anastasia Kitiashvili, \\ Associate Professor, Tbilisi State University
}

\begin{abstract}
:
Poverty has a negative impact on the cognitive, emotional, and social development of the child and in general on their well-being (Ridge, 2009; Atree, 2006; Becker, 2008). Poverty is a stigmatized social position. Poverty is one of the severe social problems in Georgia. The study aimed to explore social and psychological effects of poverty on children's everyday life. The qualitative interviews were conducted with 40 children aged 12-17 (22 girls and 28 boys) in Tbilisi. All children lived in families registered with the Social Service Agency who received social assistance from the government.

The study showed that poverty is a part of children's identity, which is negative (95\%). Compared to non-poor groups, the prestige of the in-group people decreases; "We" are poor, shy, unsuitable, unsuccessful. "they" are: rich, happy, beautiful, popular, good. In narratives, there are cases of perceived stigma and discrimination. For $95 \%$ poverty is a negative experience. It is related to a sense of fear and weakness, anxiety, shame. About $85 \%$ of the children are not involved in various social activities. They often think that they are excluded from their classmates; They are constantly afraid of mocking because of their poverty; They feel sad when their classmates go for fun or a cafe and they are not invited.

It is impotent to take into consideration the needs of children in the process of development of poverty-reduction social policy; to develop relevant support services.
\end{abstract}

Keywords: poverty, children, psychological effect, social effect. 